\title{
París, destino privilegiado del exilio español (1813-1851). A propósito de varias aportaciones historiográficas recientes
}

\begin{abstract}
Rafael Fernández Sirvent
El poeta, aquí en París, en su primera visita al doctor, ha dicho: - Usted llega de España, querido doctor, y yo me apresuro a venir a verle. De España trae usted, no hay que decirlo, una sensación profunda de dolor... Si se pudiera solificar [sic] el fluido nervioso de los que han sufrido y sufren, formaría ese fluido una masa inmensa que podríallenar los infinitos espacios sidéreos...
\end{abstract}

AZORÍN, Españoles en París, Madrid, Espasa-Calpe, 1977 (1ª edic. de 1939), p. 25.

\section{El eXILIO y París}

Si omitimos la fecha de publicación de la cita con que encabezo este ensayo bibliográfico, las palabras de Azorín adquieren un carácter transhistórico que podemos extrapolar a otros tantos exilios españoles de época contemporánea, o incluso anteriores ${ }^{1}$. En los albores del siglo XIX, París era una esplendorosa ciudad cargada de historia e idealizada por algunos mitos de difusión universal: cuna o residencia habitual de personajes ilustres; capital de un gran imperio, el napoleónico; uno de los principales centros de poder político y económico y epicentro cultural. En Manual del viajero español, de París a Londres (1851),

$1 \quad$ En esta línea, José Luis Abellán desarrolla una tesis en la que otorga al exilio el estatus de categoría explicativa de la historia de España desde el siglo XV (El exilio como constante y como categoría, Madrid, Biblioteca Nueva, 2001). Precisamente, sobre ese marco cronológico, se ha publicado una interesante visión de conjunto de los exilios españoles en la Edad Moderna y en la Edad Contemporánea en la obra colectiva Canal, Jordi (ed.), Exilios. Los éxodos políticos en la historia de España, siglos XV-XX, Madrid, Sílex, 2007. 
Antonio María Segovia, "El Estudiante", presenta una tipología de los viajeros a París, descartando a los emigrados políticos: los que buscan instrucción general (clases acomodadas), por cuestiones de salud, para realizar estudios avanzados y conocer los adelantos de una profesión, y para efectuar negocios, pues París es el verdadero centro de la moderna civilización ${ }^{2}$. Además, Francia tenía fama de ser hospitalaria con los refugiados políticos ${ }^{3}$. Ante tal panorama, es fácil entender que cientos de españoles y españolas, que por causas fundamentalmente políticas y de supervivencia hubieron de abandonar su patria en el siglo XIX, recalasen en la capital del país de al lado (Aymes, 2008, pp. 27-28), con el que los españoles estamos unidos y separados, según se quiera, vía Pirineos. Una mayoría con intensos deseos de regresar de una emigración forzosa; otros con la idea de iniciar una nueva vida en la mítica París. Solo un selecto número de este último grupo logró paladear el éxito en sus proyectos profesionales y de vida y no regresaron a España, al menos de forma permanente. Algunos, incluso, obtuvieron la nacionalidad francesa y alcanzaron cierta notoriedad en la sociedad gala. En cualquier caso, una parte importante de la historia de España se ha desarrollado y escrito en París. Eso sí: París no siempre estuvo al alcance de cualquiera, solo de unos privilegiados.

Como señala el profesor Juan Francisco Fuentes, conviene hacer una matización semántica: el vocablo que durante todo el siglo XIX y buena parte del XX designaba lo que hoy solemos entender por exilio es emigración. Mientras que la primera voz es una rara avis en la lengua española hasta 1939, la segunda se utiliza con frecuencia ya desde la época de la Revolución Francesa, momento a partir del cual adquirirá el significado de refugiado en otro país para evitar la cárcel o el peligro de muerte en su patria natal debido a razones ideológicas o políticas $^{4}$. Consciente del anacronismo conceptual, aquí se hablará a menudo de exilio/exiliado por tener hoy día prácticamente la misma carga semántica que emigración/emigrado tuvo con antelación en la época objeto de nuestra atención.

2 Aymes, Jean-René, Españoles en París en época romántica, 1808-1848, Madrid, Alianza Editorial, 2008, p. 28.

3 Sánchez Mantero, Rafael, Liberales en el exilio (La emigración política en Francia en la crisis del Antiguo Régimen), Madrid, Rialp, 1975, p. 14.

4 Fuentes, Juan Francisco, "Imagen del exilio y del exiliado en la España del siglo XIX", Ayer, no 47 (2002), p. 35; y del mismo autor, "Emigración", en Fernández Sebastián, Javier y Fuentes, Juan Francisco (dirs.), Diccionario politico y social del siglo XIX español, Madrid, Alianza Editorial, 2002, pp. 268-271; Germán Rueda, "Emigración" (pp. 460469) y Juan Francisco Fuentes (pp. 529-539), en Fernández Sebastián, J. y Fuentes, J.F. (dirs.), Diccionario político y social del siglo XX español, Madrid, Alianza Editorial, 2008. 


\section{Exilios a París}

En la última década, sobre todo, la producción bibliográfica sobre los exilios, en general, y, más en particular, el que tiene París como destino, se ha visto incrementada de un modo considerable. Artículos, diccionarios y monografías de muy diversa índole y género han contribuido a ampliar nuestro conocimiento acerca de las pautas generales y, lo que es más interesante, las muchas particularidades ("gama de grises") de los exilios y de los exiliados políticos españoles en París y sobre la vida cotidiana y las redes sociales de estos emigrados. Han aparecido obras, individuales y colectivas, que abordan de forma conjunta las condiciones de vida y las actividades de los expatriados y también de los visitantes ("turistas") españoles en París. Dos de las más completas y específicas son: Españoles en París en la época romántica, 1808-1848 (2008), del prolífico hispanista Jean-René Aymes, y París, ciudad de acogida. El exilio español durante los siglos XIX y XX (2010), obra colectiva coordinada por los profesores Fernando Martínez, Jordi Canal y Encarnación Lemus. A estas dos obras, que abordan de un modo sistemático la ciudad de París como centro receptor de diversos flujos de exiliados españoles, hemos de añadir otras sugerentes monografías de síntesis ${ }^{5}$ e investigaciones de carácter biográfico ${ }^{6}$ donde la capital francesa adquiere un papel destacado en la trayectoria de un individuo o de algún colectivo histórico. En su citada monografía, Aymes alude y saca buen provecho de las muchas biografías aparecidas en los últimos años y recoge sus principales aportaciones, además de

5 Una aproximación global al fenómeno de los exilios políticos en la España contemporánea, donde se presta también buena atención al exilio en el norte de África y en los Estados Unidos de América, en ViLAR, Juan B., La España del exilio. Las emigraciones politicas españolas en los siglos XIX y XX, Madrid, Síntesis, 2006; una síntesis más breve y divulgativa en Soldevilla, Consuelo y Rueda, Germán, El exilio español (1808-1975), Madrid, Arco Libros, 2001. Un breve estado de la cuestión acerca del exilio liberal a comienzos del siglo XIX en Ramírez, Germán, "Algunas consideraciones sobre los exilios liberales en la España del siglo XIX (1814-1834)", Anuario de estudios sobre los exilios culturales españoles, 2003, pp. 28-58 y en Butrón, Gonzalo, "El exilio liberal y afrancesado en el reinado de Fernando VII: un breve estado de la cuestión", en CASAS, José Luis y DuRÁN, Francisco (coords.), III Congreso sobre el republicanismo. Los exilios en España (siglos XIX y XX), Priego de Córdoba, Patronato "Niceto Alcalá-Zamora", 2005, vol. 2, pp. 69-83.

6 Entre otras, Calvo, José María, Ramón José de Arce: inquisidor general, arzobispo de Zaragoza y líder de los afrancesados, Zaragoza, Fundación Bicentenario de los Sitios de Zaragoza, 2008; Fernández SiRvent, Rafael, Francisco Amorós y los inicios de la educación física moderna. Biografía de un funcionario al servicio de España y Francia, Alicante, Publicaciones de la Universidad de Alicante, 2005; La PARRA, Emilio, Manuel Godoy. La aventura del poder, Barcelona, Tusquets, 2002; Luis, Jean-Philippe, L'ivresse de la fortune. A.M. Aguado, un génie des affaires, París, Payot, 2009; Rubén Puente, Armando, Alejandro Aguado. Militar, banquero, mecenas, Madrid, Edibesa, 2007; Varela Suanzes-Carpegna, Joaquín, El conde de Toreno. Biografía de un liberal (1786-1843), Madrid, Marcial Pons, 2005. 
utilizar fuentes inéditas de lo más diverso. Y es que, como bien concluye Emilio La Parra en la recensión que elabora a partir de la monografía de Nuria Alonso Garcés sobre la biografía del "liberal" aragonés Martín de Garay ${ }^{7}$, los estudios biográficos constituyen hoy día-ya pocos lo ponen en tela de juicio- un método de trabajo indefectible para relegar ciertos estereotipos historiográficos y seguir profundizando en el conocimiento de una época tan rica en matices, cambios y contradicciones como es la primera mitad del siglo XIX, cuando se consolida en España el tránsito del Antiguo Régimen a un nuevo régimen monárquico-constitucional, con los vaivenes políticos y sociales que este largo proceso histórico conlleva.

En la primera mitad del siglo XIX, Aymes (2008, pp. 23-25) distingue tres grandes episodios de emigraciones políticas en España:

1. Entre 1813-1815 miles de familias de españoles "afrancesados", que habían colaborado en mayor o menor grado con la administración bonapartista durante la guerra de Independencia, llegaron a Francia en busca de asilo. A ellos se unieron los liberales proscritos por Fernando VII en mayo de 1814 por considerar que habían adoptado una doctrina revolucionaria, quienes en su mayoría prefirieron refugiarse en Inglaterra, donde esperaban mejor acogida que en la Francia de Luis XVIII. Como apunta Juan Francisco Fuentes, es difícil que en la historia se vuelva a dar un caso como este: que tanto afrancesados como liberales, es decir, vencidos y vencedores de una guerra civil (1808-1814), tuvieran que partir juntos, pero no revueltos, al exilio 8 .

2. En 1823, tras la intervención armada de los Cien Mil Hijos de San Luis, ${ }^{9}$ se produce otra oleada de emigración liberal a Inglaterra ${ }^{10}$, Gibraltar y

7 La Parra, Emilio, "El liberalismo de Martín de Garay. Recensión de Nuria Alonso GARCÉs, Biografía de un liberal aragonés: Martín de Garay (1771-1822), Zaragoza, Institución Fernando el Católico, 2009, en Historia Constitucional, nº 11 (2010), pp. 513517: <http://www.historiaconstitucional.com/index.php/historiaconstitucional/article/ view/280/247> [consultado el 23-06-2011].

8 Fuentes, Juan Francisco, "Afrancesados y liberales", en Canal, Jordi (ed.), Exilios. Los éxodos políticos... op. cit., p. 141.

9 Destacados políticos, militares, hombres de letras, etc. tuvieron que emigrar para salvar la vida: véase algunos ejemplos en La PARRA, Emilio, Los Cien Mil Hijos de San Luis. El ocaso del primer impulso liberal en España, Madrid, Síntesis, 2007, p. 335 y ss.

10 Vicente Llorens realiza la primera gran monografía sobre el tema, donde aborda de forma conjunta el exilio español a Inglaterra entre 1823-1834, centrando su atención principal en los aspectos literarios de dicha emigración: Llorens, Vicente, Liberales y románticos. Una emigración española en Inglaterra (1823-1834), $3^{a}$ edic. ( $1^{a}$ edic. de 1954), Madrid, Castalia, 1979. 
Francia ${ }^{11}$, sobre todo, y a otros destinos más exóticos (Portugal, Bélgica, norte de África, jóvenes repúblicas sudamericanas, México, Cuba, Estados Unidos...), siendo de nuevo Francia el destino preferido. ${ }^{12}$

3. Un nuevo movimiento migratorio de menor envergadura que los anteriores se produjo en el verano de 1840, conformado principalmente por algunos opositores al regente Espartero. No obstante, a partir de 1833 (con la amnistía tras la muerte de Fernando VII) se van difuminando las fronteras entre el móvil político y la conveniencia personal, y muchos emigrados a París lo harán por propia iniciativa, para "ponerse a cubierto" al hacer patente su oposición al gobierno de turno.

El ejemplar acercamiento prosopográfico que Juan López Tabar presenta en Los famosos traidores... (2001) ${ }^{13}$ ha marcado otro hito historiográfico significativo en el estudio del colectivo afrancesado, viniendo a completar a dos de las obras a mi juicio fundamentales sobre el tema: Los afrancesados $(1953)^{14}$, de Miguel Artola y Los afrancesados. Primera emigración politica del siglo XIX... (1993) ${ }^{15}$, de Luis Barbastro. La investigación de López Tabar se cimienta sobre una nutrida base de datos elaborada mediante la contrastación de varios listados de empleados de José I y de refugiados políticos en Francia. Un censo prosopográfico compuesto por 4172 individuos, cifra que, como el mismo autor advierte, difiere de los valores reales del fenómeno del afrancesamiento. Un total de 2933 personas

11 Rafael Sánchez Mantero hace lo propio con el caso de la emigración española a Francia en el periodo posterior a 1823: Liberales en el exilio... op. cit. Merece ser destacado aquí el trabajo de Aline Vauchelle: "La emigración a Francia del clero liberal español: 18231834”, Brocar, 21 (1998), pp. 269-310. En él se ofrece una lista, con datos básicos, de algo más de un centenar de clérigos liberales refugiados en Francia.

12 Cabe destacar una última investigación sobre el tema basada en un exhaustivo censo prosopográfico de liberales en el exilio formado por 6256 individuos, cuya elaboración y estudio debemos al profesor Fuentes, Juan Francisco, "Geografía del liberalismo español en la Década Ominosa: emigración política y exilio interior", en Alberola, Armando y LarRiba, Elisabel (eds.), Las élites y la "Revolución de España" (1808-1814). Estudios en homenaje al profesor Gérard Dufour, Alicante, Universidad de Alicante-Université de Provence-Casa de Velázquez, 2010 , pp. 309-331.

13 López TABar, Juan, Los famosos traidores. Los afrancesados durante la crisis del Antiguo Régimen (1808-1833), Madrid, Biblioteca Nueva, 2001.

14 ARtola, Miguel, Los afrancesados, Madrid, Rivadeneyra, 1953. Esta obra referencial se centra en la época de la guerra de la Independencia y solo de manera epilogar se hace alguna alusión a la actuación de los afrancesados en el destierro.

15 Barbastro, Luis, Los afrancesados. Primera emigración política del siglo XIX español (18131820), Madrid, CSIC-Instituto de Culturta "Juan Gil-Albert", 1993. Se trata de la primera investigación que aborda y valora el exilio del colectivo afrancesado en su conjunto, tomando como base empírica la profusa documentación conservada en los archivos (nacionales y de asuntos exteriores) de París. 
censadas, la mayor parte de las cuales ocuparon empleos de mediana y alta responsabilidad en la administración josefina, hubieron de cruzar los Pirineos de forma apresurada a partir de 1813, aunque sin duda el número de emigrados fue superior al que las fuentes documentales nos proporcionan, como señala López Tabar. Estos afrancesados exiliados siguieron derroteros profesionales y evoluciones ideológicas de lo más variopinto y López Tabar sigue la pista a muchos de ellos, tanto a los que decidieron quedarse en Francia como a quienes en algún momento decidieron regresar a España y, no pocos, desempeñar de nuevo algún empleo público de cierta relevancia.

Como ya anunciaba al comienzo, París no estuvo al alcance de cualquier proscrito sino solo de unos pocos privilegiados ${ }^{16}$, de los refugiados más eminentes a causa de sus títulos, de su fortuna o de los cargos que ejercieron durante la época de la guerra de la Independencia (ex ministros josefinos, consejeros de Estado, diplomáticos, algunos eclesiásticos de alto rango, luego también diputados de las Cortes de Cádiz...) o durante el Trienio Liberal. Podemos hablar, pues, de un exilio de élites, que poco tiene que ver con los hacinamientos en depósitos de refugiados formados durante los estertores de la contienda franco-española y con otras dificultades encontradas por la amplia mayoría de españoles que no tuvieron otra opción más que permanecer en los departamentos del sur de Francia.

Como asevera Juan Francisco Fuentes, será sumamente difícil que en la historia se vuelva a dar un caso como este: que tanto afrancesados como liberales, es decir, vencidos y vencedores de una misma guerra civil (1808-1814), partan casi juntos, pero no revueltos, al exilio. ${ }^{17}$ De hecho, a partir de 1815 ocurre un suceso significativo: en no pocas ocasiones, a los policías franceses les cuesta diferenciar (en muchos casos no lo consiguen) a los refugiados españoles afrancesados de los refugiados liberales y es que entre un número considerable de ellos se produjo un acercamiento y se inició una colaboración cuyo fin último era destronar a Fernando VII (Aymes, 2008, pp. 25 y 49). Es más, muchos de estos antiguos enemigos durante la guerra de la Independencia estuvieron bajo sospecha de estar perpetrando juntos planes conspirativos: hombres tan encontrados apenas un par de años atrás como Francisco Amorós, el conde de Toreno, Juan Antonio Llorente, el general Espoz y Mina, el marqués de Almenara, el conde de Guzmán, Juan Antonio Melón y Ramón José de Arce, cuanto menos mantenían relaciones y frecuentaban las mismas tertulias y, además, las

16 Ver comentarios acerca del exilio español en París desde 1813 (López TABAR, 2001, p. 110 y ss.; Aymes, 2008, pp. 24 y 44-56) y después de 1823 (Sánchez Mantero, 1975, p. 85 y SS.).

17 Fuentes, Juan Francisco, "Afrancesados y liberales", en CAnal, Jordi (ed.), Exilios. Los éxodos políticos... op. cit., p. 141. 
autoridades galas los tuvo vigilados de cerca por estar bajo sospecha de urdir un complot para derrocar a los Borbones de España, Nápoles y Francia en 1816.18 Ese mismo año, José María Queipo de Llano, conde de Toreno, llegaría a pasar un par de meses en una prisión parisina, acusado de apoyar el pronunciamiento a favor de la derribada Constitución que el general Juan Díaz Porlier, cuñado de Toreno, había auspiciado en La Coruña. ${ }^{19}$ La mayoría de los emigrados a grandes y populosas capitales como París o Londres eligieron ese destino, entre otras cosas, para procurar pasar desapercibidos ante cualquier intento de vigilancia y control. Craso error de cálculo. La mina inagotable que supone el fondo documental F7 (Ministère de la Police) de los Archivos Nacionales de París demuestra de forma fehaciente hasta qué punto los refugiados políticos fueron sometidos a estrecha vigilancia.

\section{Españoles en París}

Por lo general, el perfil medio del español que por motivos políticos emigra a París en las primeras décadas del siglo XIX suele ser el de una persona que en España ha desempeñado un cargo importante y en consecuencia ha ejercido algún tipo de poder político, militar o espiritual, que, por tanto, ha gozado de una posición social distinguida y, normalmente, con un poder adquisitivo medioalto. En Francia, sin embargo, pese a que el gobierno galo acordara una pensión para dichos refugiados políticos, estos prohombres se diluyeron en la sociedad francesa y se convirtieron en "anónimos" desprovistos de poder político y económico, lo cual, en mayor o menor grado, les mermará el ánimo en un momento dado. Muchos de ellos se dedicaron a cultivar una actividad literaria o científica, o a escribir representaciones justificativas para intentar conseguir una amnistía de Fernando VII y poder así volver a su patria natal. Otros, por contra, desde los primeros momentos del exilio, tuvieron en mente iniciar una nueva vida en Francia en todos los sentidos, intentaron poner en marcha una serie de proyectos profesionales, llegando, incluso, algunos de ellos (muy pocos) a llevar su afran-

18 Fernández SiRvent, Rafael, Francisco Amorós... Biografía de un funcionario al servicio de España y Francia, op. cit., pp. 183-185; y del mismo autor "Del bonapartismo al restauracionismo borbónico. Actitud política de un realista constitucional emigrado a París: Francisco Amorós, 1808-1818", en CaSas, José Luis y Durán, Francisco (coords.), III Congreso sobre el republicanismo. Los exilios en España (siglos XIX y XX), op. cit., pp. 11-30; Calvo, José María, Ramón José de Arce..., op. cit., p. 383.

19 Varela Suanzes-Carpegna, Joaquín, El conde de Toreno..., op. cit., p. 104. Hablando de conspiraciones liberales antifernandinas en Francia, es de recibo citar el modélico estudio aparecido recientemente sobre una de estas tramas: Morange, Claude, Una conspiración fallida y una Constitución nonnata (1819), Madrid, Centro de Estudios Políticos y Constitucionales, 2006. 
cesamiento cultural y político hasta sus últimas consecuencias: la adopción de la nacionalidad francesa. Los casos más señalados de españoles que echan raíces en París, concierne casi en exclusiva a los afrancesados. Entre 1814 y 1831, 112 habían obtenido la nacionalización y 262 la habían solicitado (Vauchelle y Dufour, 1991, p. 33; Aymes, 2008, p. 313). Este fue el caso de Francisco Amorós (en 1816) ${ }^{20}$ y de Alejandro Aguado (en 1828) ${ }^{21}$. Estos ex josefinos son dos ejemplos paradigmáticos de las posibilidades que ofrecía un país como Francia, y sobre todo una ciudad cosmopolita como París, para el desarrollo profesional de individuos emprendedores en el seno de una nueva sociedad en construcción, donde mérito y capital se vislumbraban como los ingredientes básicos de la nueva fórmula del éxito y de la consecución de reconocimiento social. Sus vidas, sus actitudes, con sus evoluciones y contradicciones, son el mejor reflejo de una época de cambios y pervivencias donde tradición y modernidad, Antiguo Régimen y liberalismo-capitalismo, se muestran en constante pugna o interlocución.

En Livresse de la fortune. A.M. Aguado, un génie des affaires (2009), el profesor hispanista Jean-Philippe Luis elabora una inteligente y documentada biografía de quien llegaría a convertirse en uno de los hombres más ricos de Francia gracias a diversos negocios comerciales, bancarios y especulativos: Alejandro María Aguado, marqués de las Marismas del Guadalquivir. Un personaje camaleónico y oportunista (de los que abundaban en la época) que se mostró hostilidad a los franceses hasta la ocupación de Sevilla, para luego jurar fidelidad al rey José y luchar como edecán al lado del mariscal Soult, razón por la que se vio obligado a exiliarse a París en 1813, donde se enriquecerá y se convertirá en el banquero que mediante cuantiosos empréstitos salvará en más de una ocasión al Estado español de la bancarrota durante la Década Ominosa (cap. 5, "La poule aux oeufs d'or: les emprunts espagnols", pp. 145-183). Las relaciones de amistad y de parentesco de Aguado están presentes a lo largo de toda la obra, incluso con tablas que lo sintetizan de forma gráfica (p. 74). Se ofrecen, además, sugestivas explicaciones acerca de las distintas vías de movilidad social en la época de transición que le tocó vivir, de las redes clientelares y de los tiempos vividos por el biografiado, cosa no tan perceptible en otra documentada biografía parcial sobre Aguado escrita, esta en castellano, por Armando Rubén Puente ${ }^{22}$.

20 Jean-Baptiste Busaall presenta una reseña de la biografía de Amorós escrita por Rafael Fernández Sirvent en Mélanges de la Casa de Velázquez, 37-1 (2007), pp. 271-273: $<$ http://mcv.revues.org/3158> [consultado el 24-06-2011].

21 Claude Morange realiza una minuciosa reseña de la biografía de Aguado escrita por JeanPhilippe Luis, en Cahiers de civilisation espagnole contemporaine, 7 (2010): <http://ccec. revues.org/index3554.html> [consultado el 23-06-2011].

22 Rubén Puente, Armando, Alejandro Aguado. Militar, banquero, mecenas..., op. cit. Esta bio- 
Pese a lo que pueda pensarse, muchos de estos exiliados que en España lucharon en el mismo bando durante la guerra de la Independencia o que anteriormente habían trabajado juntos codo con codo, en París no mantuvieron relación alguna debido a desavenencias personales, envidias... Es el caso de Amorós: no se relaciona con Godoy (en verdad, pocos viejos amigos o protegidos le quedan a Godoy cuando pasa los últimos años de su vida en París), de quien fue sus ojos durante el reinado de Carlos IV para asuntos de Estado como la tentativa frustrada de colonización de Marruecos (1803-1805) y el intento de regeneración educativa que supuso el Instituto Pestalozziano de Madrid (1805-1808); aborrecía a Aguado, a quien tenía por un ambicioso miserable (juicio de valor extraído del diario personal de Amorós; en Jean-Philippe Luis, 2009, pp. 320 y 445); cesó su amistad con el general Domingo Badía y Leblich por un asunto amoroso con la hija (casada) de este, de quien era su preceptor. Sin embargo, como se ha dicho, Amorós mantendrá contacto con algunos liberales que habían sido sus enemigos durante la guerra franco-española. Los clérigos Juan Antonio Llorente 23 y Juan Antonio Melón fueron los grandes amigos de Amorós en la ciudad del Sena. En París, Francisco Amorós pudo materializar su sueño educativo, que ya había esbozado en el Madrid prebélico: establecer y difundir un singular método de educación física y moral mediante la creación de diversos establecimientos gimnásticos, primero con subvenciones gubernamentales, el Gymnase Normal Militaire et Civil (1820); ya durante el reinado de Luis Felipe de Orleans, por iniciativa propia, el primer gimnasio privado de París, el Gymnase Civil et Orthosomatique (1834) ${ }^{24}$. La fama del modelo gimnástico amorosiano traspasó las fronteras de sus "dos patrias".

Ramón José de Arce: inquisidor general, arzobispo de Zaragoza y líder de los afrancesados (2008) es otra documentada biografía escrita por José María Calvo que saca a la luz la apasionante vida y giros de tuerca de un personaje con enorme poder durante el reinado de Carlos IV y luego de José I, que acabó sus días en París, cuyo nombre "es más digno de figurar en alguna novela de Alexandre Dumas (como es el caso de Aguado en el célebre Conde de Montecristo; en JeanPhilippe Luis, 2009, p. 7) que en un Flor Sanctorum (vida de santos)", como de forma jocosa apunta Gérard Dufour en el prólogo del libro (p. 7). Arce mantuvo una vida activa en París y se conoce que su modesto piso en la capital fue punto de reunión de multitud de españoles afrancesados y liberales exiliados, hombres

grafía aborda solo los 40 primeros años de la vida de Aguado, quedando pendiente un segundo volumen sobre su faceta de mecenas de las artes, cuya publicación desconozco.

23 Dufour, Gérard, Juan Antonio Llorente en France (1813-1822), Ginebra, Droz, 1982.

24 Fernández SiRvent, Rafael, Francisco Amorós y los inicios de la educación física moderna. Biografía de un funcionario al servicio de España y Francia..., op. cit. 
de negocios, viajeros: Manuel Godoy (uno de los más habituales), Sebastián de Miñano ${ }^{25}$, José García de León y Pizarro, Alejandro Aguado, Andrés Muriel, Juan Antonio Melón, Manuel García de la Prada, Mateo Orfila, Francisco Lacoma y Fontanet... (Calvo, 2008, pp. 394, 403, 409-412). Sumamente curioso, por extraño, resulta que no haya huella de Arce en las voluminosas Memorias de Godoy.

En París, los agentes de Fernando VII no actuaban con la libertad de movimientos permitida por el sumo pontífice en Roma y también allí era más fácil rentabilizar el dinero (Aguado lo demostró, iy de qué forma!), dos de las razones por las que Manuel Godoy y Pepita Tudó decidieron trasladarse a la capital francesa en 1830, donde se adaptaron a la moda burguesa-financiera parisiense auspiciada sobre todo por el ministro Guizot con su famoso "enriqueceos" tras la entronización del "Rey burgués". Al contrario de Aguado, la aventura financiera de Godoy acabó de la peor forma posible, con pérdida de patrimonio y endeudamiento (La Parra, 2002, p. 453 y ss.). En 1836 y 1837 se publican en París (también en Madrid, Londres, Berlín...) las Memorias ${ }^{26}$ de Godoy, donde el "jubilado" príncipe de la Paz construye su imagen para la posteridad. Recientemente, Emilio La Parra y Elisabel Larriba han editado las Memorias completas de Godoy, con aclaratorias notas a pie de página y precedidas de un prolijo y encomiable estudio introductorio, que ya es obra de referencia para los estudiosos de la época ${ }^{27}$.

Los grandes cementerios de París (Père Lachaise, Montparnasse, Passy, Montmartre) son hoy día lugar de peregrinaje del turismo cultural, por la cantidad de personajes célebres que en ellos prolongan su memoria. Muchos notorios españoles en algún tiempo por motivos variados (Urquijo, Aguado, Arce, Silvela, Moratín, Kindelán, Lanz, Muriel, conde de Toreno, Zea Bermúdez, Amorós, Godoy...; en Aymes, 2008, pp. 314-320) pasan hoy totalmente desapercibidos (el majestuoso mausoleo de Aguado menos $)^{28}$ entre tales celebridades de las artes, las ciencias y la política. Valgan sus biografías como representación testimonial de aquellos tiempos de luces y sombras, de glorias y penurias, que innumerables españoles vivieron y compartieron en París.

25 Morange, Claude, Paleobiografía (1779-1819) del "Pobrecito holgazán", Sebastián de Miñano y Bedoya, Salamanca, Ediciones de la Universidad de Salamanca, 2002.

26 El título de la primera edición en castellano fue Memorias del Príncipe de la Paz, o sean memorias críticas y apologéticas para la historia del reinado del señor D. Carlos IV de Borbón.

27 Godor, Manuel, Memorias, edición de Emilio La Parra y Elisabel Larriba, Alicante, Servicio de Publicaciones de la Universidad de Alicante, 2008. Magnífica edición en un solo volumen que se basa en la primera edición en castellano, citada en la nota anterior. Godoy fallece en París en 1851, fecha que he tomado de un modo convencional para poner meta cronológica a este ensayo bibliográfico.

28 Una fotografía representativa del mausoleo de Alejandro Aguado puede verse en $<$ http:// fr.wikipedia.org/wiki/Alexandre_Aguado> [consultado el 28-06-2011]. 

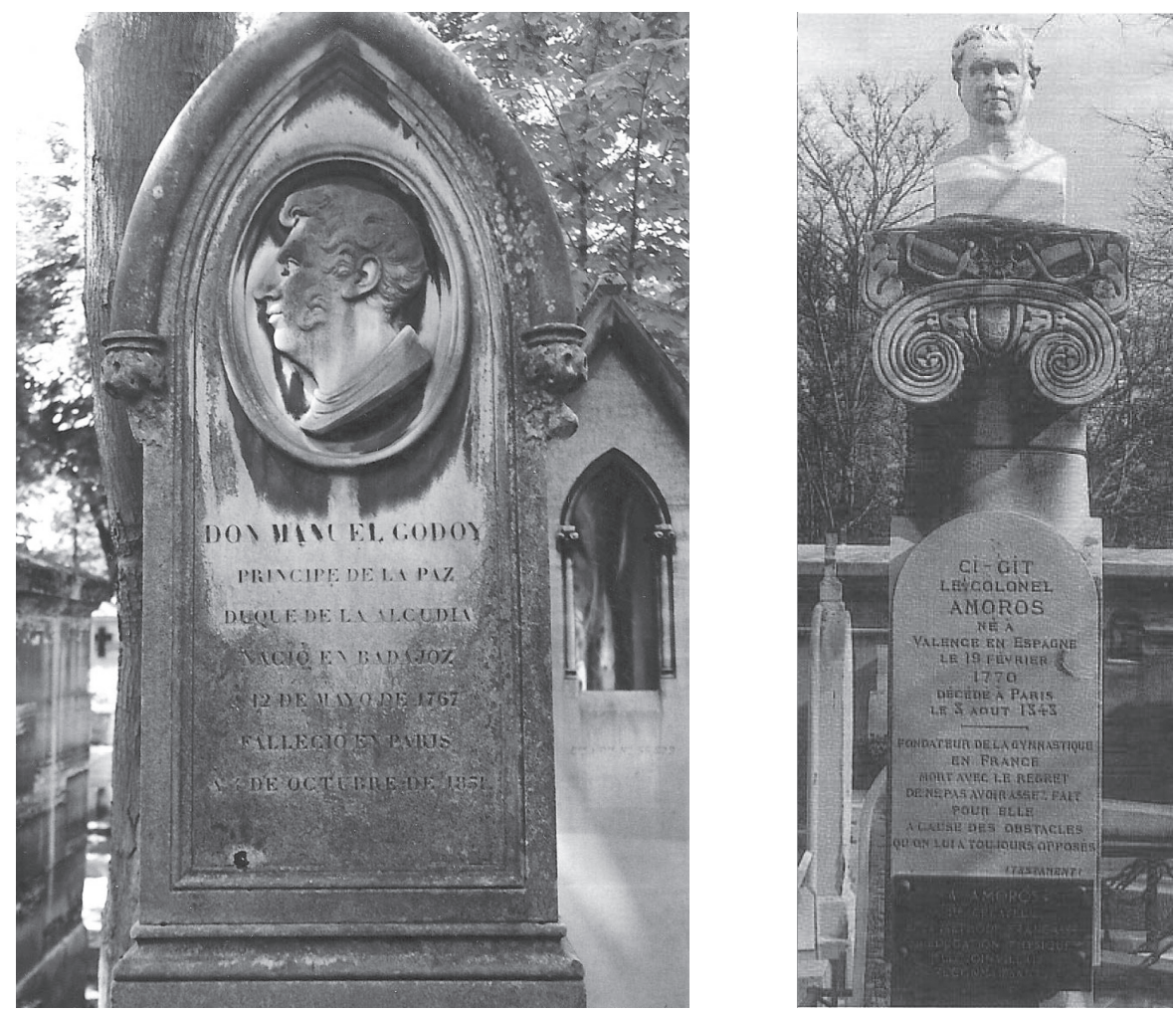

Tumbas de Manuel Godoy y de Francisco Amorós.

Cementerios Père Lachaise y Montparnasse, respectivamente. París.

Fotos del autor. (2001).

Son bastantes más, obviamente, los insignes españoles que visitaron o residieron en París a lo largo del siglo XIX (como cuantiosos son los estudios referidos a personajes destacados que padecieron, en una o en varias ocasiones, el 
sabor amargo del exilio ${ }^{29}$ o que trabajaron en París para el gobierno español ${ }^{30}$ ), pero el lector ávido de información histórica contrastada y fidedigna habrá de hacer el esfuerzo de alimentar su biblioteca con una selección de las obras aquí referidas.

\section{ÚLTIMAS APORTACIONES BIBLIOGRÁFICAS ${ }^{31}$}

AbelLán, José Luis (2001), El exilio como constante y como categoría, Madrid, Biblioteca Nueva, 221 págs.

Aymes, Jean-René (2008), Españoles en París en la época romántica, 1808-1848, Madrid, Alianza Editorial, 357 págs.

Barbastro GiL, Luis (2002), "La emigración liberal a Francia: españoles en París (1823-1834)", en Enfrontaments civils: postguerras i reconstruccions, II Congrés Recerques), vol. 1, Lleida, Pagès Editors.

Butrón Prida, Gonzalo (2005), "El exilio liberal y afrancesado en el reinado de Fernando VII: un breve estado de la cuestión", en Casas Sánchez, José Luis; Durán Alcalá, Francisco (coords.), III Congreso sobre el republicanismo: Los exilios en España (siglos XIX y XX), vol. 2, Priego de Córdoba, Patronato "Niceto AlcaláZamora", pp. 69-83.

Calvo Fernández, José María (2008), Ramón José de Arce: inquisidor general, arzobispo de Zaragoza y líder de los afrancesados, Zaragoza, Fundación Bicentenario de los Sitios de Zaragoza, 477 págs.

Canal, Jordi, ed. (2007), Exilios. Los éxodos politicos en la historia de España, siglos XV-XX, Madrid, Sílex, 282 págs.

29 Entre otros, los estudios de los liberales Antonio Alcalá Galiano, Álvaro Flórez Estrada y Francisco Martínez de la Rosa: SÁnchez García, Raquel, Alcalá Galiano y el liberalismo español, Madrid, CEPC, 2005; Varela Suanzes-Carpegna, Joaquín (coord.), Álvaro Flórez Estrada (1766-1853): política, economía, sociedad, Oviedo, Junta General del Principado de Asturias, 2004; Pérez De La Blanca, Pedro, Martínez de la Rosa y sus tiempos, Barcelona, Ariel, 2005. Estos y otros cientos de liberales - "huérfanos" aún de biógrafo- que hicieron de París su morada interina, cuentan al menos con una breve semblanza en la monumental -como de costumbre- obra del prolífico profesor Alberto Gil Novales: Diccionario Biográfico de España (1808-1833). De los orígenes del liberalismo a la reacción absolutista, Madrid, Fundación Mapfre, 2010.

30 Es el caso, por ejemplo, de Salustiano Olózaga, embajador en París durante la regencia de Espartero, quien cuenta con un completo estudio hasta la época de su nombramiento como presidente del Consejo de Ministros de España: Gómez Urdáñez, Gracia, Salustiano de Olózaga. Élites políticas en el liberalismo español (1805-1843), Logroño, Servicio de Publicaciones de la Universidad de La Rioja, 1999.

31 En los libros colectivos citados se detallan solo aquellos capítulos que abordan algún aspecto relacionado con el tema y la cronología de este ensayo bibliográfico. 
Canal, Jordi (2007), "Los exilios en la historia de España", en Canal, Jordi, ed., Exilios. Los éxodos políticos en la historia de España, siglos XV-XX, Madrid, Súlex, pp. 11-35.

Casas Sánchez, José Luis; Durán Alcalá, Francisco, coords. (2005), III Congreso sobre el republicanismo: Los exilios en España (siglos XIX y XX), vol. 2, Priego de Córdoba, Patronato "Niceto Alcalá-Zamora".

Fernández Sirvent, Rafael (2005), Francisco Amorós y los inicios de la educación física moderna. Biografía de un funcionario al servicio de España y Francia, Alicante, Publicaciones de la Universidad de Alicante, 393 págs.

Fernández SiRvent, Rafael (2005), "Del bonapartismo al restauracionismo borbónico. Actitud política de un realista constitucional emigrado a París: Francisco Amorós, 1808-1818", en Casas Sánchez, José Luis y Durán Alcalá, Francisco, coords., III Congreso sobre el republicanismo: Los exilios en España (siglos XIX y XX), vol. 2, Priego de Córdoba, Patronato "Niceto Alcalá-Zamora", pp. 11-30.

Fuentes Aragonés, Juan Francisco (2002), "Imagen del exilio y del exiliado en la España del siglo XIX", Ayer, no 47, pp. 35-56.

Fuentes Aragonés, Juan Francisco (2007), "Afrancesados y liberales", en Canal, Jordi, ed., Exilios. Los éxodos políticos en la historia de España, siglos XV-XX, Madrid, Sílex, pp. 137-166.

Fuentes, Juan Francisco (2010), "Geografía del liberalismo español en la Década Ominosa: emigración política y exilio interior", en Alberola, Armando y LARRIBA, Elisabel, eds., Las élites y la "Revolución de España" (1808-1814). Estudios en homenaje al profesor Gérard Dufour, Alicante, Universidad de Alicante-Université de Provence-Casa de Velázquez, pp. 309-331.

Gil Novales, Alberto (2010), Diccionario Biográfico de España (1808-1833). De los orígenes del liberalismo a la reacción absolutista, 3 vols., Madrid, Fundación Mapfre, 3406 págs.

Godoy, Manuel (2008), Memorias, Alicante, Publicaciones de la Universidad de Alicante, edición de Emilio La Parra López y Elisabel Larriba (memorias completas con estudio introductorio y notas), 1.985 págs.

La Parra López, Emilio (2002), Manuel Godoy. La aventura del poder, Barcelona, Tusquets, 582 págs.

Lemus, Encarnación, ed. (2002), "Los exilios en la España contemporánea", Ayer, $\mathrm{n}^{\circ} 47$.

López TABAR, Juan (2001), Los famosos traidores. Los afrancesados durante la crisis del Antiguo Régimen (1808-1833), Madrid, Biblioteca Nueva, 406 págs.

Luis, Jean-Philippe (2009), L'ivresse de la fortune. A.M. Aguado, un génie des affai- 
res, París, Payot, 511 págs.

Martínez, Fernando, Canal, Jordi, Lemus, Encarnación, eds. (2010), París, ciudad de acogida. El exilio español durante los siglos XIX y XX, Madrid, Marcial PonsSociedad Estatal de Conmemoraciones Culturales, 413 págs.

Morange, Claude (2002), Paleobiografía (1779-1819) del "Pobrecito holgazán", Sebastián de Miñano y Bedoya, Salamanca, Ediciones de la Universidad de Salamanca, 402 págs.

Pérez de la Blanca Sales, Pedro (2005), Martínez de la Rosa y sus tiempos, Barcelona, Ariel, 495 págs.

Ramírez Aledón, Germán (2003), "Algunas consideraciones sobre los exilios liberales en la España del siglo XIX (1814-1834)", Anuario de estudios sobre los exilios culturales españoles, pp. 28-58.

Rubén Puente, Armando (2007), Alejandro Aguado. Militar, banquero, mecenas, vol. 1, Madrid, Edibesa, 445 págs.

Sánchez García, Raquel (2005), Alcalá Galiano y el liberalismo español, Madrid, Centro de Estudios Políticos y Constitucionales, 516 págs.

Sánchez Mantero, Rafael (2002), "Exilio liberal e intrigas políticas", Ayer, no 47, pp. 17-34.

Soldevilla, Consuelo y Rueda, Germán (2001), El exilio español (1808-1975), Madrid, Arco Libros, 91 págs.

Varela Suanzes-Carpegna, Joaquín (2004), Álvaro Flórez Estrada (1766-1853): política, economía, sociedad, Oviedo, Junta General del Principado de Asturias, 527 págs.

Varela Suanzes-Carpegna, Joaquín (2005), El conde de Toreno. Biografía de un liberal (1786-1843), Madrid, Marcial Pons, 263 págs.

VILAR, Juan B. (2006), La España del exilio. Las emigraciones políticas españolas en los siglos XIX y XX, Madrid, Síntesis, 495 págs.

\section{Alguna bibliografía sobre el tema publicada en el siglo XX}

Artola, Miguel (1953), Los afrancesados, Madrid, Rivadeneyra (última edición en Alianza Editorial, 2008).

Aymes, Jean-René (1987), Los españoles en Francia (1808-1814). La deportación bajo el Primer Imperio, Madrid, Siglo XXI.

Azorín (1977), Españoles en París, $7^{a}$ edic. (1ª edic. de 1939), Madrid, EspasaCalpe. 
Barbastro Gil, Luis (1993), Los afrancesados. Primera emigración política del siglo XIX español (1813-1820), Madrid, CSIC-Instituto de Cultura "Juan Gil-Albert" (Diputación de Alicante).

Dufour, Gérard (1982), Juan Antonio Llorente en France (1813-1822), Ginebra, Droz.

Dufour, Gérard, Vauchelle, Aline, (1991) "Les Espagnols naturalisés français et les Espagnols ayant obtenu l'autorisation de fixer leur domicile en France de 1814 à 1831", en Exil politique et migration économique. Espagnols et Français aux XIXème-XXème siècles, París, Éditions du CNRS.

Gómez Urdáñez, Gracia (1999), Salustiano de Olózaga. Élites políticas en el liberalismo español (1805-1843), Logroño, Servicio de Publicaciones de la Universidad de La Rioja.

La Parra López, Emilio (1997), "Godoy en el París de Luis Felipe. La atracción de una imagen de la prosperidad", en Aymes, J.-R. y Fernández Sebastián, J., eds., Limage de la France en Espagne (1808-1850), París-Bilbao, Presses de la Sorbonne Nouvelle-Universidad del País Vasco, pp. 79-86.

Llorens Castillo, Vicente (1979), Liberales y románticos. Una emigración española en Inglaterra (1823-1834), $3^{\text {a }}$ edic. aumentada ( $1^{a}$ edic. de 1954), Madrid, Castalia.

Marañón, Gregorio (1947), Españoles fuera de España, Buenos Aires, EspasaCalpe.

Romero Tobar, Leonardo (1997), "Españoles en París. Contactos de románticos españoles y escritores franceses", en Aymes y Fernández Sebastián, eds., L'image de la France en Espagne (1808-1850), París-Bilbao, Presses de la Sorbonne NouvelleUniversidad del País Vasco, pp. 215-226.

Sánchez Mantero, Rafael (1975), Liberales en el exilio (La emigración política en Francia en la crisis del Antiguo Régimen), Madrid, Rialp.

URía Riu, Juan (1955), "Flórez Estrada en París (1830-1834)", Archivum. Revista de la Facultad de Filología, t. 5, pp. 39-76.

Vauchelle, Aline (1998), "La emigración a Francia del clero liberal español: 1823-1834”, Brocar. Cuadernos de investigación histórica, 21, pp. 269-310. 